\title{
Preparativos del viaje de Diego de Nicuesa para poblar la Tierra Firme. Sevilla y los mercaderes del comercio atlántico (1509)
}

por

\author{
Carmen Mena García \\ Universidad de Sevilla
}

\begin{abstract}
Desvelamos en estas páginas aspectos absolutamente novedosos de la expedición de Alonso de Ojeda y Diego de Nicuesa a la Tierra Firme. En especial, nos preocupamos por investigar los preparativos realizados en solitario por Nicuesa en Sevilla, cuyos gastos y vicisitudes quedaron reflejados tanto en el libro de cuentas del tesorero Matienzo como en los registros notariales hispalenses. Todo un entramado mercantil aflora en nuestra pesquisa con un notorio predominio de los comerciantes vascos y genoveses interesados en el comercio atlántico, que ahora participan activamente al servicio de la flotilla de Tierra Firme.

Palabras Clave: Diego de Nicuesa; Alonso de Ojeda; Sevilla y el comercio atlántico; escrituras de crédito a riesgo; Juan de la Cosa; Tierra Firme; comerciantes vascos, genoveses y burgaleses.
\end{abstract}

Al Rescate de monstruos, SERPIENTES Y ANimAles DE TODA ESPECIE ${ }^{1}$

Cuando comenzaba el nuevo siglo los navegantes españoles habían reunido las pruebas suficientes como para demostrar lo que el Gran Almirante se había negado a admitir: la existencia de un nuevo continente. Fracasados los proyectos de la Junta celebrada en Toro en 1505 y una vez superadas las dificultades surgidas en Castilla, a raíz de la muerte de la reina Isabel y de

1 Mi sincero agradecimiento por la orientación y las facilidades prestadas por el personal del Archivo General de Indias de Sevilla (en adelante AGI) en la consulta de la documentación que fundamenta buena parte de este trabajo. 
Felipe de Habsburgo, el rey Fernando, que salió fortalecido de aquella crisis, se mostró decidido a retomar los asuntos de las Indias y a fines de 1507 convocó en Burgos ${ }^{2}$ a los hombres más expertos, comenzando por el obispo Juan Rodríguez de Fonseca, su principal consejero en estas cuestiones, y varios navegantes de primera fila, como Américo Vespucio, quien ahora iba a ser distinguido con el cargo de Piloto Mayor, al paleño Vicente Yáñez Pinzón y a otros dos pilotos experimentados: Juan Díaz de Solís, natural de Lepe, fue uno de los elegidos, pues había viajado al servicio de los portugueses hasta aguas orientales desconocidas por los españoles; el otro fue el cántabro Juan de la Cosa, que en 1500 había explorado por primera vez el golfo de Urabá junto a Rodrigo de Bastidas $^{3}$, y cuatro años después retornó al mismo escenario, esta vez como capitán general y piloto, acompañado por Alonso de Ojeda $^{4}$. Uno de los principales acuerdos adoptados en la Junta de Burgos fue el de buscar en las Indias un estrecho, un canal o mar abierto que acortase el camino hacia las islas de las Especias. Díaz de Solís y Yáñez Pinzón recibieron instrucciones de navegar desde el Golfo de Honduras descubierto por Colón hacia el norte y el oeste y es posible que finalmente lograran recorrer el litoral del golfo mexicano, llegando algo más al norte de Tampico ${ }^{5}$. Otra importante decisión de esta famosa Junta se refirió a la ocupación de la Tierra Firme por Alonso de Ojeda y Diego de Nicuesa, de cuyos preparativos sevillanos nos ocuparemos en estas páginas.

Tradicionalmente se ha venido considerando que esta nueva empresa, que se dirige al escenario visitado por Rodrigo de Bastidas y por Colón en el que sería su cuarto y último viaje al Nuevo Mundo, tenía como propósito la búsqueda de un estrecho o vía marítima hacia el Oriente. Pero de las instrucciones entregadas por la Corona a los flamantes gobernadores no se deduce semejante propósito. Simplemente, como observa con acierto Sauer, «el plan consistía en retomar las actividades que desde diez años antes tenían lugar en

2 La Junta se retrasó hasta marzo de 1508.

3 Viaje de Rodrigo de Bastidas en colaboración con Juan de la Cosa, Vasco Núñez de Balboa y Andrés de Morales. La capitulación firmada en Sevilla, 6 de junio de 1500. El original no se conserva. (Un traslado de la capitulación en Sevilla, 8, marzo, 1503: AGI, Patronato, 26, R.1). Al final del viaje se le concede a Juan de la Cosa el cargo de alguacil mayor del gobernador de Urabá. Véase: Catálogo de Juan de la Cosa, 2010: 57-58.

${ }_{4}^{4}$ La expedición parte hacia Urabá en septiembre de 1504 una vez que Juan de la Cosa firma su asiento con los armadores de los barcos que componen su flotilla. Archivo Histórico Provincial de Sevilla, Sección Protocolos Notariales (en adelante APS), n. ${ }^{\circ}$ inventario 3222, f. 392 r-394r. Véase Szászdi y León Borja, 2001 y Sauer, 1984: 245-258.

5 Sauer, 1984: 250. 
estas costas, pero ahora con una organización formal» ${ }^{6}$. Y es posible que, tal y como sugiere Giménez Fernández, persiguiera en última instancia un proyecto de mayor alcance como era el debilitamiento del virreinato colombino: «la última meta de la política de Fernando el Católico en Indias» ${ }^{7}$.

La noticia de que la Junta de Burgos había aconsejado al monarca poner en marcha una expedición para explorar y colonizar las tierras continentales se difundió rápidamente por todos los rincones hasta llegar a oídos de Ojeda y Nicuesa. En aquellos momentos Alonso de Ojeda residía en Santo Domingo, pero fue informado por su amigo y confidente Juan de la Cosa, destacado miembro de la comisión de expertos, quien lo representó oportunamente en las negociaciones para la jefatura. Nicuesa lo tuvo más fácil, pues acababa de llegar a la corte en compañía del bachiller Antonio Serrano, como procurador de los vecinos de La Española. En efecto, cuando se difundió la noticia de que la Corona preparaba una nueva empresa a las tierras americanas, no faltaron pretendientes a la jefatura, pero finalmente la corona adoptó una decisión salomónica y eligió no a uno, sino a dos de los candidatos mejor situados: Alonso de Ojeda y Diego de Nicuesa, ambos favoritos de Juan Rodríguez de Fonseca, «el gran hacedor de los asuntos indianos» y de Lope de Conchillos, el influyente secretario del rey Fernando ${ }^{8}$.

Aunque todavía vigoroso y capaz, Alonso de Ojeda era un viejo conocido de la Corte y un baquiano en Indias. Había participado con desigual fortuna en numerosos viajes a las costas americanas y se relacionaba con algunos de los más expertos navegantes de la época, en particular con Juan de la Cosa, a quien profesaba una sincera amistad. De origen hidalgo, aunque venido a menos, había nacido en Cuenca y durante algunos años fue paje del poderoso duque de Medinaceli, don Luis de la Cerda. En 1493 decidió viajar al Nuevo Mundo y lo hizo acompañando a Colón en su segundo viaje. Desde entonces no dejó de probar fortuna. En Santo Domingo, donde residía, se había ganado el reconocimiento de sus vecinos por sus campañas militares contra los indios en especial en la captura del cacique Canoabo o en la sangrienta batalla de Jáquimo. Con el paso de los años, Ojeda se había consagrado como un avezado navegante y explorador de las costas americanas, tan experto en fracasos como inaccesible al desaliento; famoso por la destreza con su espada

6 Ibidem: 255.

7 Giménez Fernández, 1953, vol. I: 23 y ss.

8 Sobre las andanzas de Ojeda y Nicuesa en la Tierra Firme y la capitulación que sustenta la empresa de 1509 puede ampliarse información en Sauer (1984) y en nuestra última obra (2011), en especial véase capítulo 2, ambos trabajos constituyen el soporte fundamental de estas páginas introductorias. 
y sus numerosas correrías de duelista, valiente hasta la temeridad, pero pobre de solemnidad, en definitiva, un aventurero sin éxito a la espera de que la fortuna se pusiera de su lado.

Diego de Nicuesa era un hidalgo culto y de modales exquisitos, natural de Torredonjimeno (Jaén), y al igual que Ojeda había prestado sus servicios en una poderosa casa nobiliaria: nada menos que la de don Enrique Enríquez, tío del rey Fernando el Católico. Llegó más tarde a las Indias, pues lo hizo en 1502 formando parte de la magna expedición encomendada al nuevo gobernador de Santo Domingo fray Nicolás de Ovando. Se había avecindado en Concepción de la Vega y en pocos años había conseguido lo que Ojeda no lograría en toda su vida. Disfrutaba de una fortuna valorada en torno a los 6.000 pesos de oro y era reputado como uno de los encomenderos más ricos e influyentes de la isla La Española. Tenía, además, una pequeña flotilla de la que supo sacar buen provecho empleándola en el tráfico de indios esclavos, que eran capturados en «las islas inútiles» y luego vendidos al mejor postor en La Española. En Sevilla mantenía asiduos contactos de negocios con algunos de los mercaderes genoveses más reputados, como los Doria, los Spínola o los Centurión. En suma, un hombre de éxito.

La capitulación con Ojeda y Nicuesa para anexionar la Tierra Firme fue firmada por el rey y refrendada por Conchillos en Burgos, el 9 de junio de 1508. La empresa sería privada, aunque la Corona se reservaba una estrecha supervisión sobre la misma y tendría una duración inicial de cuatro años. Se otorgaron dos demarcaciones separadas para cada uno de los capitanes de la expedición: una para los territorios situados al este del golfo de Urabá y otra para los del oeste. A Alonso de Ojeda se le adjudicó la porción oriental —Urabá- más tarde bautizada como la Nueva Andalucía, que comprendía desde el cabo de la Vela hasta la mitad del golfo. Como señala Sauer, esta concesión confirmaba y ampliaba para Ojeda su antiguo título de gobernador de Coquibacoa (en la actual Venezuela) duplicando en extensión sus límites iniciales hasta alcanzar por occidente el golfo de Urabá. Juan de la Cosa, el socio de Ojeda, recibió el segundo puesto de la expedición, siendo distinguido por la corona con el cargo de lugarteniente «para que en las partes donde él (Ojeda) no estuviere, sea nuestro capitán en su nombre y donde estuviere sea su teniente». Oviedo asegura que el monarca quiso recompensar al famoso piloto de Santoña «por lo que había ya hecho antes en aquella costa, e porque era diestro en la mar e sabía las cosas de aquella tierra», y obligó a Ojeda a que lo llevase con él en este nuevo viaje ${ }^{9}$. Además el experimentado marino y

\footnotetext{
9 Fernández de Oviedo, 1959, vol. III: 137-138.
} 
cartógrafo, quien no olvidemos que había negociado la capitulación representando a Ojeda, recibió la confirmación de su antiguo oficio de alguacil mayor del gobernador de Urabá, obtenida el 3 de abril de 1503, por su vida y la de su heredero ${ }^{10}$. Por último el bachiller Martín Fernández de Enciso, un acaudalado encomendero de La Española dispuesto a invertir en la empresa, fue nombrado por Ojeda su alcalde mayor.

Diego de Nicuesa recibió Veragua: la concesión más occidental, al otro lado del golfo de Urabá hasta el cabo de Gracias a Dios. Las expectativas en riquezas auríferas de este territorio visitado por Colón obligan a considerarlo «el premio mayor» ${ }^{11}$. Nicuesa consiguió, en definitiva, la pieza más codiciada. No podía sospechar las penalidades que le aguardaban en aquel infierno dorado. Veragua era el nombre de un territorio de límites imprecisos que había sido otorgado sin tener en cuenta el descubrimiento ni los títulos colombinos. Igual puede decirse de la isla de Jamaica, también descubierta por Colón aunque todavía permanecía sin ocupar. Una cláusula de la capitulación otorgada a Ojeda y Nicuesa, que nadie ha sabido explicar hasta ahora, les concedía la gobernación conjunta de la citada isla, aunque subordinada a la autoridad de La Española en donde pronto iba a gobernar Diego Colón, el hijo del Almirante.

La empresa de la Tierra Firme podía desembocar en la colonización definitiva de los dos territorios gemelos, pero en estos momentos tal propósito no parece preocupar demasiado. Como ya se advirtió, «la capitulación de Burgos contemplaba el poblamiento de las tierras de Urabá y Veragua por los hombres de Ojeda y Nicuesa, más como una posibilidad - y en ese caso se concedía el derecho a la ocupación territorial-, que como una obligación o un objetivo inmediato ${ }^{12}$. En cambio, se ignoraba cualquier tipo de ordenamiento económico o gubernativo de los nuevos territorios. Eso sí, hay un interés manifiesto en los capítulos ya habituales relativos a las capturas de esclavos ${ }^{13}$ y rescates con los indios, tanto de metales y productos valiosos como de «seres monstruosos»y animales de cualquier especie, según se recoge expresamente en el texto: "por estas capitulaciones vos sean defendidas rescatar e haber

10 AGI, Indiferente, 1961, L.1, fol. 55v-56r, 57r-v y 58r-v. Algunos de estos nombramientos se encuentran recogidos en la obra de Fernández de Navarrete, 1964, vol. II: 79 y ss.

11 Sauer, 1984: 256

12 «Item, que si vosotros o los que con vosotros se juntaren quisiéredes quedar allá para edificar casas o estancias o pueblos en los lugares y asientos que lo podáis hacer...». Sauer, 1984: 254. Mena, 2011: 116.

13 La autorización se refería a la costa de Cartagena y a las islas de Baru, San Bernardo e Isla Fuerte. 
en otra cualquier manera oro e plata e guanines e otros metales, aljófar e piedras preciosas y perlas, e monstruos e serpientes y animales e pescados e aves, especiería y de otro género e droguería e otras cualesquier cosas...». Y desde luego, lo que más parece interesar es el producto de la minería de oro y plata, del cual la Corona se reservaba al principio el décimo, elevando sucesivamente el porcentaje hasta alcanzar el quinto acostumbrado.

Ambos concesionarios - Ojeda y Nicuesa - fueron distinguidos en la capitulación con el título de capitán de sus respectivos territorios, pero en principio y tal vez con extremada cautela no se les asignó cargo gubernativo alguno. En estos momentos se vivía en la Corte una situación delicada. Se había denegado a Ovando su tercera solicitud de relevo mientras que Diego Colón presionaba cuánto podía reclamando sus derechos a los territorios descubiertos por su padre, el Gran Almirante. Sin embargo, nada impidió que se creasen dos nuevas gobernaciones en las Indias. Desde hacía algunos años la política estatal se mostraba firme en sus propósitos de debilitar los privilegios colombinos, y la reina Juana ratificó el asiento dado por su padre mediante una disposición fechada en Burgos, el 9 de junio de 1508, en la que concedía el título de gobernador y capitán, con jurisdicción civil y criminal, para Ojeda y Nicuesa ${ }^{14}$. Dos meses más tarde, de manera repentina, Diego Colón fue nombrado gobernador de las Indias por un decreto fechado en Arévalo el 9 de agosto de 1508 .

Puesto que la empresa era privada, los capitulantes debían correr con la mayor parte de los gastos de la expedición. No obstante, la corona proporcionó ayuda en armas, alimentos y franquicias, de manera que finalmente, y como ya veremos, la expedición supuso un desembolso considerable para la real hacienda de algo más de dos millones de maravedís. Tanto Nicuesa como Ojeda obtuvieron permiso en su asiento para reclutar — si así lo deseaban — un límite de ochocientos hombres y llevarlos consigo a las nuevas tierras continentales: doscientos se engancharían en la península y los seiscientos restantes en La Española. A todos ellos se les concedía por un tiempo determinado pasaje franco, alimentos y algunas piezas de armaduras para proteger sus cuerpos, a razón de un escudo de madera o «tablachina», un coselete o coraza ligera y una babera para cubrir boca, barba y quijada. También se les permitió que llevasen cuarenta indios experimentados en la minería aurífera para que pudiesen adiestrar en el oficio a los indios de la Tierra Firme, así como otros cuatrocientos de las demás islas vecinas para que sirviesen a los

14 El título de gobernadores de Urabá y Veragua fue expedido conjuntamente en un mismo documento para Alonso de Ojeda y Diego Nicuesa. AGI, Indiferente, 1961, L.1, F.53v$54 \mathrm{r}$. 
españoles, al igual que lo estaban haciendo con los vecinos de Santo Domingo ${ }^{15}$. Como centros nodrizas, imprescindibles para el sostenimiento de las nuevas colonias continentales en los primeros años, fueron señaladas las islas de La Española y Jamaica. Cada uno de los concesionarios adquirió asimismo el compromiso de construir a sus expensas en un plazo de dos años y medio dos fortines de piedra en el territorio de su jurisdicción y otros dos de las mismas características en Jamaica. La Corona designó como alcalde de las fortalezas de Urabá a Silvestre Pérez y de las de Veragua a Alonso de Quiroga. Para las de Jamaica no se tomó ninguna decisión. Estos nombramientos y la utilización de Jamaica disgustaron a Diego Colón porque lo consideraba una flagrante violación de sus derechos. Desde luego, llegado el momento se mostró escasamente colaborador con los expedicionarios y con el nuevo asentamiento de las tierras continentales y solo de mala gana apoyó con envíos ridículos y con manifiesta renuencia a los desesperados colonos del Darién.

Sin perder tiempo, Nicuesa y Juan de la Cosa abandonaron Burgos y se dirigieron a Sevilla para comenzar la recluta. Había que conseguir hombres, barcos, alimentos, armas y toda clase de suministros para la empresa: abrieron listín de enganche, tocaron cajas, hicieron sonar trompetas y desplegaron banderas anunciando que una nueva expedición se preparaba para las Indias. El gran piloto de Santoña sabía que Ojeda era pobre de solemnidad y, por tanto, poco o nada iba a aportar a la empresa. Por eso se comprometió de antemano a facilitar de su escasa hacienda lo que bien podía; el resto lo consiguió a duras penas recurriendo a la generosidad de los amigos y a la usura de los prestamistas. Nicuesa lo tuvo más fácil. Era rico y disponía de crédito entre algunos de los más importantes mercaderes afincados en Sevilla. Estos le ayudaron a preparar su expedición sin demasiados impedimentos.

\section{Una nUeVa flota SE aPRESTa en SeVILla}

Los libros del primer tesorero de la Casa de la Contratación, Sancho de Matienzo, constituyen una fuente extraordinaria para el conocimiento detallado de todas las vicisitudes que rodearon a los expedicionarios a Indias ${ }^{16}$. El

15 Real Cédula a Nicolás de Ovando. Burgos, 9 de junio de 1508, AGI, Indiferente, 1961, L.1. Y otra de la misma fecha y destinatario dando licencia para sacar cuarenta indios expertos en sacar oro.

16 Bien pudimos demostrarlo en nuestra obra sobre los preparativos de la gran armada que llevó Pedrarias a Castilla del Oro (1513-1514): Mena, 1998. También debemos al profesor Ladero Quesada dos magníficos estudios: 2002; 2008, basados en las fuentes contables, concretamente en los libros registros del tesorero Matienzo (1503-1521). Por último no pode- 
tesorero formó tres tipos de «Libros de cargo y data de la tesorería»: la Cuenta General, el Manual y el Mayor con informaciones paralelas y referencias entrelazadas que son de consulta obligada para cualquier investigador de este primer periodo ${ }^{17}$. En realidad la mayor parte de los datos seguros que conocemos de Juan de la Cosa y de otros famosos navegantes proceden de estos detalladísimos libros de Sancho de Matienzo, quien en palabras de M. ${ }^{\mathrm{a}}$ Antonia Colomar, bien pudiera considerarse «el cronista económico de esta primera época de Indias» ${ }^{18}$. Conociendo sobradamente su valor, volvemos una vez más a estos registros contables para documentar en esta ocasión un viaje del que hasta ahora no se conocían otros datos más que los que proporcionan las crónicas de la época y algún que otro documento oficial: el que prepara en Sevilla entre 1508 y 1509 Diego de Nicuesa, en su nombre y en el de Alonso de Ojeda, con destino a la Tierra Firme. Como observa el profesor Ladero, esta expedición que constituye «el principal empeño del año 1509, aparte de la flota que llevó el almirante Diego Colón a La Española», es la última de las mencionadas en las cuentas del tesorero Matienzo, «cuya experiencia en aquellas operaciones le convertía, sin duda, en la persona más adecuada para organizar y contabilizar en el futuro otras armadas fueran cuales fuesen sus dimensiones e importancia» ${ }^{19}$. Sin duda, tal y como ya tuvimos ocasión de demostrar, el momento estelar de Matienzo tuvo lugar entre 1513 y 1514 con motivo de la imponente flota que el segoviano Pedrarias Dávila condujo a Castilla del Oro y que fue magistralmente gestionada por el funcionario y sus ayudantes de la Casa $^{20}$.

Los preparativos dieron comienzo en la primavera de 1508, un año antes de que zarpase la expedición. El 30 de abril el rey Fernando dirigía una misiva a Nicolás de Ovando concediéndole las mercedes solicitadas por los vecinos de Santo Domingo a través de sus procuradores, los ya mencionados Antón Serrano y Diego de Nicuesa, que habían llegado a España ${ }^{21}$. Este último con dos propósitos: actuar como procurador de los vecinos de la isla y

mos olvidar los trabajos realizados hace ya algunos años por E. Otte sobre los documentos del Consejo Real, del Archivo de Simancas: 97-98 (Madrid, 1964a): 475-504 y 93-94 (Madrid, 1963): 519-530.

17 AGI, Contratación, 4674.

18 Juan de la Cosa, 2010: 56.

19 Ladero, 2002: 53-54.

20 Además de los libros de la tesorería, las fuentes oficiales sobre la expedición de Nicuesa, que son abundantes, se encuentran reunidas casi en su totalidad en el cedulario de Indiferente General, 1961 y 418 del Archivo General de Indias de Sevilla.

21 Para un mejor conocimiento de las peticiones de los procuradores, véase Arranz, 1991: 108 y ss. 
conseguir la tan ansiada jefatura de la Tierra Firme. Seguramente Nicuesa respiró satisfecho en aquellos días. Por fin había logrado lo que tanto deseaba. Tras las interminables esperas para ser recibido por los consejeros más cercanos al monarca, especialmente Conchillos — su protector-, aquellas largas y angustiosas entrevistas habían dado su fruto y habían demostrado una vez más sus dotes para moverse como pez en el agua en los despachos más influyentes. Todo aquel que lo conocía sabía que el hidalgo jienense era un auténtico cortesano de modales exquisitos, también un comerciante genuino que embaucaba a todos con sus sabias reflexiones y gracejo andaluz. «Persona muy cuerda y palanciana y graciosa en decir», apunta Las Casas ${ }^{22}$. Es probable que todas estas virtudes le auparan hasta el éxito.

El 9 de junio de 1508 el monarca daba órdenes a los oficiales de la Casa de la Contratación para que abasteciesen de mantenimientos y de todas las cosas necesarias a la gente que viajaba con Nicuesa, y en otra misiva de la misma fecha disponía que los citados oficiales guardasen y cumpliesen el asiento que se había tomado con Nicuesa, Ojeda y Juan de la Cosa ${ }^{23}$. Muy pronto los diligentes funcionarios se pusieron manos a la obra. La primera tarea y quizás la más difícil consistía en reclutar los barcos necesarios para el envío de las remesas solicitadas por los colonos de La Española. Es sabido que en estos tempranos años la escasez de efectivos navales constituía un mal endémico incluso en aquellos países de larga tradición marítima y lo mismo podría decirse respecto a los hombres de mar. Por eso, los oficiales de la Casa ante la disyuntiva de fletar las embarcaciones — «tomar a sueldo»- o comprarlas a los armadores, optaron por esta última. Se decidió comisionar a Juan de la Cosa, que disponía de buenos contactos en el litoral del vecino reino portugués, para llevar a cabo esta misión y hacia allí se dirigió el piloto con una carta de recomendación del monarca a comienzos de enero de 1509. Tres meses más tarde, Juan de la Cosa ha regresado a Sevilla. El 15 de abril lo encontramos en el muelle de las Muelas con dos carabelas latinas conseguidas en Lisboa. La de mayor porte era La Concepción de Nuestra Señora y había sido adquirida a Andrés González por 90.000 maravedís. La carabela menor, llamada Santa Ana Rosa, era propiedad del también armador portugués Juan Castaño y costó casi la mitad que la anterior (47.000 mrs.). Sin perder tiempo, ambas embarcaciones fueron preparadas para la larga travesía atlántica: se las hizo redondas, sustituyéndoles las velas latinas originales y luego fueron sometidas a diversas labores de carpintería hasta ponerlas a punto. El maestre y piloto de la mayor era Diego Delgado, natural de Palos, mientras que al

\footnotetext{
22 Las Casas, 1957: L.2, cap. 52.

23 AGI, Indiferente, 1961, L.1.
} 
frente de la menor viajaba otro paleño llamado Alonso Enríquez. Se completó también la dotación de las carabelas. Alguien consideró que una tripulación de diez hombres por barco resultaría suficiente para aquella ocasión, de lo cual deducimos que se trataba de embarcaciones pequeñas; probablemente la carabela mayor no debía superar los cincuenta toneles ${ }^{24}$. Por último, los oficiales de la Casa adquirieron todo lo necesario para el viaje: bizcocho, vino, tocino, aceite y otros productos alimenticios ya habituales en la navegación trasatlántica e incluso mesas y manteles para los oficiales de los barcos. Ya en Sanlúcar, y antes de que las naos zarpasen, el alguacil de la Casa, Lorenzo de Pinelo, proporcionó a las dos carabelas nuevos refuerzos: otras dos botas de vino, dos quintales de bastina, así como carne, aceite y candelas. El tesorero Matienzo anotó en sus libros de cuentas que la compra de las dos carabelas, su equipación, abastos y sueldo de la gente de mar, así como la «cargazón» enviada a los oficiales de La Española, había supuesto un desembolso a las arcas reales de 1.310 .485 maravedís ${ }^{25}$.

Mientras los oficiales de la Contratación se afanaban en Sevilla en los preparativos de las dos carabelas que iban a ser enviadas con refuerzos a los colonos de Santo Domingo, realizaban al mismo tiempo todas las compras necesarias para el viaje de Diego de Nicuesa a la Tierra Firme, que quedaron fielmente reflejadas en el libro de cuentas del tesorero Matienzo con esta anotación: "Cuenta del costo de los mantenimientos y armas y pasaje que se dan a Diego de Nicuesa, gobernador de Veragua, por sí y en nombre de Alonso de Ojeda, gobernador de Urabá, por virtud de una capitulación fecha entre $\mathrm{Su}$ Alteza y los dichos gobernadores, cuyo traslado está en el libro de traslados de Urabá e Veragua, que comienza en la primera hoja que es sobre la población de la Tierra Firme» ${ }^{26}$. Una vez más, nos hallamos en presencia de una empresa privada con una importante cobertura estatal, ya que aunque la capitulación con Nicuesa y Ojeda precisaba rotunda que debía ser «a vuestra costa e minción», la Corona concedió para la expedición generosas partidas de víveres, animales y armas, y subvencionó el pasaje y la alimentación de un contingente que inicialmente se preveía que podía alcanzar, como se dijo, a un total de ochocientos hombres.

${ }^{24}$ El cómputo realizado sobre los barcos que integraban la flota que llevó Pedrarias al Darién en 1514 revela una media de 1 marinero por cada 4,5 toneles. Mena, 1998: 157-158.

25 AGI, 4674, I. El listado completo de la «cargazón» fue dado a conocer por Ladero, 2008: 331-335.

26 AGI, Contratación, 4674, L.1. Ladero, 2008: 327- 328; 337-338. 


\section{Comerciantes y manufacturas vascas en la flota de Nicuesa}

En nuestro trabajo sobre la armada de Pedrarias de 1513-1514 tuvimos ocasión de constatar algo que ya resulta suficientemente conocido: la fuerte participación vasca, tanto en los preparativos como en los abastos y dotación marinera de esta flota ${ }^{27}$. Ciertamente los vascos no quedaron relegados de la empresa americana, muy por el contrario, se incorporaron de inmediato a la misma, poniendo a su servicio la dilatada experiencia de un pueblo laborioso, volcado al mar desde siglos y experto en el mundo de los negocios. Como señalaba E. Otte, los vascos se distinguían por su fuerte apego a la tierra de origen y mostraban un fuerte grado de cohesión social y profesional: preferían asociarse o colaborar con sus paisanos y, aún en la distancia, no se desligaban de su cultura y de su lugar de origen ${ }^{28}$. Por otro lado, muchos de los cargos más influyentes de la administración del Estado y de las Indias en aquellos años estaban desempeñados por vascos ${ }^{29}$. La nómina es muy extensa y suficientemente conocida. Los funcionarios de la Casa de la Contratación (ahora Matienzo, Recalde e Isásaga, los dos últimos vascos) eran los principales responsables de la organización de las flotas, de su avituallamiento, selección de tripulaciones y de todos los demás aspectos relacionados con esta importante atribución. No debe extrañar, por tanto, que desde esta posición privilegiada «inclinasen la balanza en favor del País Vasco y de sus ferrerías, sus industrias navales y sus hombres de la mar» ${ }^{30}$. Un rápido repaso a las anotaciones contables sobre la flota de Nicuesa nos está indicando que la participación de los vascos en la empresa sigue siendo destacada: ocupando puestos de responsabilidad en la organización y abasto de la flota de Nicuesa, no solo como proveedores sino también como hombres de máxima confianza de los oficiales de la Contratación, encontramos a comerciantes vascos bien conocidos por su participación en la Carrera de Indias, tales como Juan Sánchez de Recalde (¿guardaba algún vínculo con el contador Juan López de Recalde?), Domingo de Ochandiano, sobrino político del Dr. Matienzo y más tarde contador de la Casa de la Contratación, Martín de Lizarraza y Nicolás Sánchez de Aramburu, vecino de Azcoitia. Subraya el profesor Ladero que este último debió de ser hombre notable y de experiencia, pues fue enviado a la corte de Francia para obtener «el despacho de la nao Colina, que había arribado al puerto de Brest por causas fortuitas», y fue encargado de traer consigo - se-

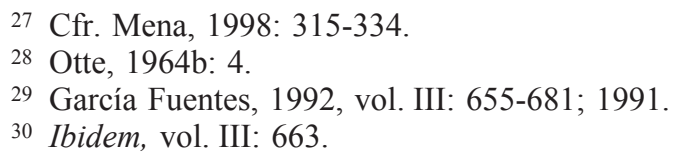


guramente por tierra desde Lisboa- el oro que transportaba ${ }^{31}$. En efecto, las cuentas de la tesorería demuestran que en diversas ocasiones los oficiales eligieron a Aramburu para desempeñar algunas misiones «oficiales» como su representante o delegado, ya fuera solo o en compañía de otros. Y así una data de 1509 revela cómo el citado Aramburu junto a Pedro de Ribota realizaron un viaje a la corte transportando 6.000 ducados «que para su Alteza con ellos enviamos» y cobraron 11.875 maravedís por el encargo ${ }^{32}$. No cabe duda de que Aramburu distaba mucho de ser un simple mercader de ferrerías, pues existen sobradas muestras de que mantuvo por algunos años lazos estrechos con sus paisanos vascos, los oficiales de la Contratación, gozó de su confianza y se benefició de tales relaciones. Tal y como ya tuvimos ocasión de demostrar, la fuerte participación vasca en la preparación y abastecimiento de armadas oficiales o por cuenta de la Corona se repite en 1513. Tanto Nicolás Sánchez Aramburu como Domingo de Ochandiano y Domingo de Lizarraza, un conocido banquero público que opera en Sevilla en estos años y envía mercancías y esclavos a las Indias, probablemente familiar o paisano de este Martín de Lizarraza, participarán activamente en el suministro de la gran flota encomendada a Pedrarias para Castilla del Oro en 1513-151433. La presencia de dos vascos — Recalde e Isásaga - al frente de la Casa favoreció sin dudarlo esta relación, que se vio abonada por el prestigio de que gozaban las ferrerías, la fabricación de armamentos y la industria naval de la cornisa cantábrica.

Todos ellos suelen actuar en comandita. En efecto, un asiento del libro del tesorero Matienzo indica que este abonó en 22 y 27 de septiembre de 1509 a Pedro de Recibal y Domingo de Ochandiano 12.378 maravedís por el flete y averías del armamento para la flota que Juan Sánchez de Recalde y Sancho Martínez de Feguimo (Heguino), ambos vecinos de Azcoitia «cargaron en Vizcaya en sus naos de la armazón que ende se hace para el viaje de Nicuesa» ${ }^{34}$. Y en otro asiento anterior consta que ambos recibieron, entre el $15 \mathrm{de}$ enero y el 16 de marzo de 1509, 2.500 ducados para la compra del citado armamento «en la provincia de Guipúzcoa y condado de Vizcaya... para el

31 Ladero, 2003: 58. Ladero, 2008: 318, D504.

32 Los ejemplos son numerosos: el 27 de febrero de 1516 consta en un asiento de la tesorería que se pagó al citado Aramburu 1.360 maravedís «por inspeccionar las naos de Lope Sánchez y Cristóbal Beços, que están en Sanlúcar, embargadas por orden de la Casa, para que nadie pudiera pasar a ellas sin licencia de la Casa». Ladero, 2008: 329, D568; 452, D1398.

33 Mena, 1998: 274, 315 y ss.

34 En otro asiento se dice que para transportar el armamento citado se utilizó la nave de otro armador vasco, llamado Ochoa de Sarasua, que era vecino de Motrico. AGI, Contratación, 4674, L.I., 508 v. 
viaje de la población de Tierra Firme de Nicuesa y Ojeda» ${ }^{35}$. Como proveedores de la flota en Sevilla y avalistas de Nicuesa figuran, asimismo, los mercaderes guipuzcoanos Martín de Lizarraza y Nicolás Sánchez de Aramburu. Esta práctica no resulta inusual pues, como ya puso de relieve A. M. Bernal, existen sobradas muestras de las implicaciones de ambos personajes en numerosas operaciones de crédito marítimo durante los primeros años de la Carrera $^{36}$.

\section{PROVISIONES PARA OCHOCIENTOS HOMBRES}

A finales de mayo de 1509, el flamante gobernador de Veragua se hizo cargo de las remesas de alimentos para sus expedicionarios. Como era habitual en los cálculos del abasto de cualquier tripulación y pasaje, lo primero que se contemplaban eran las raciones de pan y vino, pues ambas constituían la base fundamental en la dieta de cualquier viajero. El doctor Matienzo había comprado al mercader Martín de Lizarraza 212,5 quintales de bizcocho, cien para el sustento durante cuarenta días de los doscientos hombres que viajaban a cuenta de la Corona, desde Sevilla a La Española y desde allí a la Tierra Firme, a razón de 20 onzas (575 gramos) de pan a cada uno por día, que era lo usual en el rancho de la marinería. Los oficiales tenían conocimiento de que el viaje entre Santo Domingo y la Tierra Firme podía durar unos quince días y para este tiempo calcularon los abastos de los otros 600 hombres, que serían reclutados en la isla, y en los que se emplearían los 112,5 quintales restantes del material que suministraron los bizcocheros Diego de Granjeda y Juan de Mojados, ya amasado y cocido. Seguramente el vino adquirido para la flotilla de Nicuesa procedía de Manzanilla (Huelva), pues sabemos que las 1.594 arrobas y dos azumbres fueron transportadas por la vía de las «Nueve Suertes». El cálculo de las raciones de vino fue realizado con extraordinaria generosidad y al igual que en el caso anterior se contempló la duración de los dos trayectos del viaje: Sevilla-La Española (para 200 hombres) y desde aquí a la Tierra Firme (para 800). En el tiempo de las navegaciones oceánicas las tripulaciones de los barcos solían recibir un litro diario de vino y dos de agua para su viaje. En esta ocasión, los hombres de Nicuesa recibieron nada menos que tres cuartillos ${ }^{37}$ por día, es decir, litro y medio de vino. Además Matien-

\footnotetext{
35 Ladero, 2008: 327-328.

36 Bernal, 1993a: 164. Otte, 1996: 133 y 1964b: 55.

37 El cuartillo: medida castellana para líquidos que equivalía a 0,512 litros. Era la cuarta parte de una azumbre.
} 
zo proporcionó a Nicuesa 3.800 libras de carne, calculadas a razón de media libra diaria (228 gramos) para cada hombre, que habrían de alternarse con otras 4.700 libras de pescado distribuidas en una porción similar, así como dos cahices de habas y garbanzos, 12 quintales de queso, 21 arrobas de aceite, 116 arrobas de vinagre de Cazalla de la Sierra (Sevilla) y una cantidad no precisada de ajos. Parte del aceite y del vinagre procedían de una partida que estaba almacenada en la Casa y que había sobrado de la proyectada armada de la Especiería. Los futuros pobladores de la Tierra Firme recibieron también un nutrido repertorio de armas ofensivas y defensivas, así como munición en cantidad: en concreto cuarenta quintales de pólvora que fueron adquiridas al lombardero Maestre Cristóbal para la artillería de las cuatro fortalezas proyectadas en la defensa del nuevo territorio.

Provisiones y armamento que se dan a Diego de Nicuesa Para los 800 HOMBRES QUE DEBE CONDUCIR A LA TIERRA FIRME

\begin{tabular}{|c|c|c|c|}
\hline Producto & Cantidad & Precio & Total \\
\hline Bizcocho & 212,5 quintales & $25 \mathrm{mrs} . /$ quintal & $5.312,5 \mathrm{mrs}$. \\
\hline Vino & 1.594 arrobas y 2 azumbres & $45 \mathrm{mrs} /$ arroba $^{38}$ & 92.316 mrs. $^{39}$ \\
\hline Carne & 3.800 libras & 5,5 mrs./libra & $20.900 \mathrm{mrs}$. \\
\hline Pescado & 4.700 libras & 5,5 mrs./libra & $25.850 \mathrm{mrs}$. \\
\hline Haba y Garbanzo & 2 cahices & 3 reales/fanega & $2.448 \mathrm{mrs}$. \\
\hline Queso & 12 quintales & $140 \mathrm{mrs}$./arroba & $6.620 \mathrm{mrs}$. \\
\hline Aceite & 21 arrobas & & 2.442 maravedís \\
\hline Vinagre & 4 pipas (116 arrobas) & & $4.184 \mathrm{mrs}$. \\
\hline Ajos & & & 500 maravedís \\
\hline Pólvora & $\begin{array}{l}40 \text { quintales («para las cuatro fortalezas») } \\
388 \text { libras (compradas en Bilbao) } \\
50 \text { libras (para espingardas; también } \\
\text { en Bilbao) }\end{array}$ & $1.700 \mathrm{mrs} . /$ quintal & $\begin{array}{l}69.900 \mathrm{mrs} .{ }^{40} \\
9.700 \mathrm{mrs} . \\
1.700 \mathrm{mrs} .\end{array}$ \\
\hline Pelotas & 32 & & $768 \mathrm{mrs}$. \\
\hline Coseletes & 400 (comprados en Marquina) & & $320.000 \mathrm{mrs}$. \\
\hline Petos & 400 (comprados en Marquina) & & $194.000 \mathrm{mrs}$. \\
\hline Casquetes & 800 & & \\
\hline Baberas & 800 & & \\
\hline Tablachinas & $\begin{array}{l}800 \text { (guarnecidas con armas reales, } \\
\text { compradas en Bilbao) }\end{array}$ & & $30.400 \mathrm{mrs}$. \\
\hline
\end{tabular}

38 Coste del vino sin las vasijas.

39 Coste total del vino, vasijas, aros de hierro de los toneles y fletes.

40 El monto total incluye los treinta barriles en que se envasó la citada pólvora. 
Provisiones y ARMAMento Que Se dAN A Diego de Nicuesa PARA los 800 HOMBres QUE DEBE CONDUCIR A LA TIERRA FIRME (Continuación)

\begin{tabular}{|c|c|c|c|}
\hline Producto & Cantidad & Precio & Total \\
\hline Arcabuces & $\begin{array}{l}40 \text { (de } 7 \text { palmos de hierro fundido, } \\
\text { con sus caballetes) } \\
40 \text { («de la suerte menor, de longor de } \\
7 \text { palmos») }\end{array}$ & & $\begin{array}{l}56.250 \mathrm{mrs} . \\
15.000\end{array}$ \\
\hline \begin{tabular}{|l|}
$\begin{array}{l}\text { Lombardas } \\
\text { (grandes) }\end{array}$ \\
\end{tabular} & 16 & & $209.652 \mathrm{mrs}$ \\
\hline $\begin{array}{l}\text { Lombardas } \\
\text { (medianas y } \\
\text { pequeñas) }\end{array}$ & 80 & & \\
\hline
\end{tabular}

Fuente: AGI, Contratación, 4674, L.1.

Como ya vimos, la Corona se había comprometido a correr con los gastos del pasaje de los expedicionarios de Nicuesa y Ojeda, a razón de dos ducados y cuarto por cada uno. A última hora se acordó que de los 200 hombres reclutados en Sevilla, 150 viajarían a bordo de los barcos de Nicuesa, mientras que los 50 restantes embarcarían en las dos carabelas de $\mathrm{Su}$ Alteza adquiridas por Juan de la Cosa en Portugal y que navegaban a Santo Domingo en su compañía. Los comerciantes vascos Martín de Lizarraza y Nicolás Sánchez de Aramburu se ofrecieron a adelantar el dinero necesario. Finalmente se acordó que estos percibirían 2.250 ducados en tres pagos aplazados: el primero de 450 ducados, una vez certificada la llegada de los 150 hombres a La Española (puesto que los 50 restantes viajaban en barcos de la Corona y no percibían pasaje en ese trayecto); el segundo de 900 ducados, cuando el total de los 800 hombres (200 más 600) zarpase desde Santo Domingo, y el tercero, de otros 900 ducados, cuando se tuviese constancia de que la expedición había llegado finalmente a su destino ${ }^{41}$.

\section{Barcos, prestamistas y mercaderes en la flota de Tierra Firme}

El primero y principal objetivo de Nicuesa consistió en hacerse con un número de barcos suficientes. No resulta tarea fácil porque la nutrida flota de Santo Domingo, que acaba de zarpar con el virrey Colón a comienzos de junio de 1509, se ha apropiado de los mejores barcos y de los pilotos más

${ }^{41}$ Los registros de la tesorería constatan los sucesivos abonos de estas cantidades. Cfr. Ladero, 2002: 151. 
expertos, pero Nicuesa es un hombre de recursos y después de numerosas negociaciones consigue hacerse con cuatro embarcaciones. La primera que adquiere es la nao San León, también conocida como La Zabra, de unos 115 o 120 toneles de porte, «más o menos», y no la encuentra en Sevilla sino en El Puerto de Santa María. Su propietario es un maestre vasco, natural de Bilbao, llamado Iñigo de Arteche. El contrato de compraventa realizado el 22 de febrero de 1509 ante el escribano de Sevilla Diego López se firma a conformidad de ambas partes por 400 ducados, a pagar en dos plazos, la mitad con el acta de la escritura y la otra mitad en un pago aplazado ${ }^{42}$. A continuación y para la citada nao, contrata los servicios del maestre y piloto Juan de Ledesma, avecindado en el barrio sevillano de San Vicente. Las otras dos embarcaciones adquiridas por Nicuesa son dos carabelas. Se trata de la Santiago, maestre Andrés García Niño, vecino de Moguer y la Santa María del Cabo, maestre Pedro de Umbría, paisano del anterior, sobre cuyos cascos el 11 de mayo y el 18 de junio se conciertan dos préstamos a la gruesa con el mercader genovés Alejandro Cattaneo (Alessandro Catano) y el sevillano Alonso Alemán ${ }^{43}$. La última de las embarcaciones es una nao de 120 toneles, llamada La Trinidad, y para ella el 8 de agosto Nicuesa contrata como maestre a Juan Farfán, otorgándole al mismo tiempo poderes para que admita tripulación y mercancías ${ }^{44}$. Al citado maestre pertenece una escritura de riesgo presentada ante los oficiales de la Casa de la Contratación el 15 de junio de 1508 - seguramente con anterioridad a la adquisición de la nao por Nicuesa- por valor de 400 ducados. En la misma aparecen como fiadores del maestre varios vecinos de Sevilla entre los que destaca Juan de Caicedo (Quicedo), el mismo que meses después será nombrado veedor de las fundiciones de Tierra Firme. Asimismo, participan en el negocio crediticio los

42 AGI, Contratación, 4.943 y APS, 5.829. Libro del año 1509, fecha: 22 de febrero. Oficio X, Lib. I. Escribanía Diego López.

${ }^{43} \mathrm{La}$ información la proporciona Otte, 1964a, nota 30. En nuestras pesquisas, tanto en el AGI como en el APS, apenas encontramos información sobre las dos carabelas mencionadas por Otte, maestres, mercancías embarcadas, o algún préstamo a riesgo relacionado con ellas. Una excepción es este reconocimiento de deuda que efectúa Diego de Nicuesa ante el escribano Juan Ruiz de Porras, el 7 de abril de 1509 en el cual se alude a la Santa María del Cabo. Dice así: «Diego de Nicuesa, señor y capitán de la nao y carabela nombradas La Cabra y Santa María del cabo, respectivamente, se obliga a pagar a Martín de Saucedo, mercader, 362 ducados de oro que le prestó para abastecer dichas nao y carabela en el viaje que habían de hacer al puerto de Santo Domingo en la isla Española». Catálogo, vol. I: 1930, reg. 624.

44 Libro del año 1508, 8 de agosto. Oficio XV. Lib. II, Escribanía Bernal González Vallesillo. El documento notarial se publica íntegro en el apéndice IV del Catálogo, vol. I: 1930. 
mercaderes genoveses Gaspar y Batista Centurión, Batista Cattaneo, Ambrosio de Spínola, Benito de Pumar, el empresario aragonés Juan Sánchez de la Tesorería, los mercaderes burgaleses Pedro de Santo Domingo y Francisco de Villegas y el vasco Juan de Arriaga; sin olvidar a Diego de Nicuesa, del cual consta que el 17 de octubre de 1508 «sacó a cambio de Pedro de Santo Domingo y Francisco de Villegas sobre las mercaderías que diz que tiene cargadas en la nao de que es maestre Juan de Farfán 380 ducados de principal e cambio» ${ }^{45}$.

Nuestro maestre Juan Farfán, al igual que otros ilustres marineros andaluces, como los Niño, los Quintero, Camacho, Yáñez, con presencia dominante en la Carrera, viaja con frecuencia a las Indias, como «maestre marinero» ${ }^{46}$, compaginando la actividad estrictamente náutica con la del comercio y transporte de mercancías por cuenta de acaudalados empresarios, o bien en comandita. En abril de 1510 - ya está de vuelta en Sevilla - todavía al servicio de Nicuesa como maestre de La Trinidad, y aún sigue involucrado en el tráfico trasatlántico. En la fecha citada, fleta en nombre de Nicuesa la citada nao al corredor de lonja sevillano Alonso de Ojeda (que no hay que confundir con el compañero de aventuras de Nicuesa) para que pueda embarcar 30 toneladas de mercancías con destino al puerto de la Plata en Santo Domingo. En 1512 - tras la muerte de Nicuesa - da un poder a Rodrigo Cueto, estante en La Española, para que cobre de Juan Rodríguez el importe de 5.000 ladrillos que él mismo le había entregado para que lo vendiese en la isla ${ }^{47}$. Juan de Ledesma, el maestre de la San León, se involucra de igual forma en el tráfico, ya sea transportando vino o cargamentos de tocinos, lienzos, camisas, calzones, harinas y pasas, siempre en sociedad con Nicuesa, con Juan de Caicedo o con ambos conjuntamente.

45 «Autos provistos en la Casa de la Contratación para que los maestres puedan tomar dinero a riesgo sobre sus naos, 1507-1613». AGI, Contratación, 4981, fol. 45.

46 Bernal (1993b, vol. I: 105-125) denomina así a aquellos maestres, mayoritariamente andaluces, que «por razones profesionales gobernaban naos de señores que actuaban como socios capitalistas, quienes contratan las mayores cantidades de dinero por el sistema de préstamos a riesgos y cambios». Y a continuación precisa que «en cierto modo la presencia de tales maestres marineros como doble comanditario — navegación y comercio- de los dueños de los barcos era una clara continuación del sistema bajomedieval imperante en el mundo mediterráneo que, sin modificaciones sustanciales, se traspasa a la navegación atlántica durante la primeras décadas». Muchos de estos pasan a convertirse, a partir de 1530 en que el sistema se vuelve obsoleto, en «maestres señores de naos».

47 Libro del año 1510. Fecha: 12 de abril. Oficio I, Lib. I. Escribanía de Mateo de la Cuadra: Catálogo, 1998, vol. II: reg. 39 y APS, 1508, Libro del año 1512. Fecha: 29 de marzo. Oficio XV, Lib. I. Escribanía de Bernal González Vallesillo. 
La flotilla de Diego de Nicuesa (Sevilla, 4 de septiembre de 1509)

\begin{tabular}{|l|l|l|}
\hline \multicolumn{1}{|c|}{ Tipo de barco } & \multicolumn{1}{|c|}{ Nombre } & \multicolumn{1}{c|}{ Maestre } \\
\hline nao (115 o 120 toneles) & San León (La Zabra) & Juan de Ledesma \\
\hline carabela & Santiago & $\begin{array}{l}\text { Andrés García Niño, } \\
\text { vecino de Moguer }\end{array}$ \\
\hline carabela & Santa María del Cabo & $\begin{array}{l}\text { Pedro de Umbría, } \\
\text { vecino de Moguer }\end{array}$ \\
\hline nao (120 toneles) & La Trinidad & Juan de Farfán \\
\hline
\end{tabular}

A. M. Bernal afirma que todo el que se trasladaba a Indias era un mercader en potencia, ajustándose a las mismas pautas seguidas por marineros y mercaderes: «obtenían a crédito el dinero para comprarlas (las mercancías) o las adquirían al fiado, otorgando en uno y otro caso escritura de riesgo o cambio a favor del acreedor ${ }^{48}$. De todo este decisivo capítulo de la financiación del tráfico y del comercio interesa destacar lo siguiente. En primer lugar, Jose M. ${ }^{a}$ Oliva asegura que «la fórmula crediticia utilizada casi exclusivamente en la Carrera de Indias desde sus inicios fue, como ya explicara Tomás de Mercado en 1569, la del crédito a riesgo de mar, tipo de préstamo con carácter hipotecario en el que la devolución solo es obligada una vez superado el riesgo que corre o, en otras palabras, una vez conseguida la finalidad para la que se obtuvo. Naturalmente en estos créditos los intereses alcanzaban tipos muy superiores a los de los préstamos corrientes». En segundo lugar, y a pesar de estar expresamente prohibido, en ocasiones el crédito se realizaba no en dinero sino en las mercancías embarcadas. En estos tempranos años solía estipularse que el pago de la deuda se efectuaría en un plazo que oscilaba entre veinte y treinta días desde que la nave llegaba al puerto de destino. Estas operaciones de crédito para financiar la Carrera movilizaron importantes capitales y permitieron la llegada masiva de productos extranjeros a las Indias, así como la salida a los mercados extranjeros de la plata americana ${ }^{49}$.

48 Cfr. Bernal, 1993ª:159, Martínez Shaw y Oliva Melgar, 2005.

49 Martínez Shaw y Oliva Melgar, 2005: 63-64. 
Escrituras De CRÉDito a RIESGo Suscritas PARA la flota De Diego Nicuesa $(1508-1509)^{50}$

\begin{tabular}{|c|c|c|c|c|}
\hline Otorgante & $\begin{array}{l}\text { Prestamistas } \\
\text { y cargadores }\end{array}$ & Origen & Valor & $\begin{array}{l}\text { Objeto de la } \\
\text { escritura }\end{array}$ \\
\hline $\begin{array}{l}\text { Diego Nicuesa, } \\
\text { Juan de Ledesma } \\
\text { y Juan de Carcedo }\end{array}$ & Pedro Caballero, & & 45 ducados & $\begin{array}{l}\text { préstamo sobre } \\
\text { navío }\end{array}$ \\
\hline $\begin{array}{l}\text { Juan Farfán y } \\
\text { Cristóbal Maya, } \\
\text { cómitre }\end{array}$ & Fernando de Venegas & & & $\begin{array}{l}\text { préstamo de } 150 \\
\text { ducados }\end{array}$ \\
\hline Juan de Caicedo & Diego de Ervás & mercader sevillano & $7.500 \mathrm{mrs}$. & préstamo \\
\hline Diego de Nicuesa & Diego de Ervás & mercader sevillano & $61.000 \mathrm{mrs}$. & préstamo \\
\hline $\begin{array}{l}\text { Diego de Nicuesa, } \\
\text { Juan de Caicedo y } \\
\text { Juan de Ledesma }\end{array}$ & $\begin{array}{l}\text { Alexandre Cattaneo } \\
\text { Batista Centurión }\end{array}$ & $\begin{array}{l}\text { mercaderes } \\
\text { genoveses }\end{array}$ & $153.062 \mathrm{mrs}$. & préstamo \\
\hline Diego de Nicuesa & $\begin{array}{l}\text { Diego Rodríguez de } \\
\text { Grajeda }\end{array}$ & $\begin{array}{l}\text { cómitre sevillano y } \\
\text { maestre }\end{array}$ & $9.500 \mathrm{mrs}$. & préstamo \\
\hline $\begin{array}{l}\text { Juan de Ledesma, } \\
\text { Pedro Mir, Martín } \\
\text { de Salcedo y Juan } \\
\text { de Caicedo }\end{array}$ & Bernardo de Grimaldo & genovés & $45.000 \mathrm{mrs}$. & préstamo \\
\hline Juan Farfán & $\begin{array}{l}\text { Gaspar Centurión } \\
\text { Batista Centurión } \\
\text { Batista Cattaneo } \\
\text { Ambrosio de Spínola } \\
\text { Benito de Pumar } \\
\text { Juan Sánchez de la } \\
\text { Tesorería } \\
\text { Pedro de Santo } \\
\text { Domingo } \\
\text { Francisco de Villegas } \\
\text { Juan de Arriaga } \\
\text { Diego de Nicuesa }\end{array}$ & $\begin{array}{l}\text { mercaderes } \\
\text { genoveses } \\
\text { aragonés } \\
\text { burgalés } \\
\text { burgalés } \\
\text { vasco } \\
\text { Capitán de la reina, } \\
\text { estante en Sevilla }\end{array}$ & 400 ducados & préstamo \\
\hline La Corona & $\begin{array}{l}\text { Martín de Lizarraza y } \\
\text { Nicolás Sánchez } \\
\text { Aramburu }\end{array}$ & mercaderes vascos & \begin{tabular}{|l|}
2.250 \\
ducados
\end{tabular} & préstamo \\
\hline Diego de Nicuesa & $\begin{array}{l}\text { Benito Doria y } \\
\text { Ambrosio Spínola }\end{array}$ & mercader genovés & $126.250 \mathrm{mrs}$. & préstamo \\
\hline El mismo & Iñigo Franco & & 225 ducados & préstamo \\
\hline El mismo & Batista Centurión & mercader genovés & 165 ducados & préstamo \\
\hline El mismo & Benito Pumar & mercader genovés & 75 ducados & préstamo \\
\hline
\end{tabular}

50 «Autos provistos en la Casa de la Contratación para que los maestres puedan tomar dinero a riesgo sobre sus naos (1507-1613)», AGI, Contratación, 4981. «Libros de conocimientos de escribanos (1509-1660)». AGI, Contratación, 4943 y APS, 1508, 5.829 y 9.107. 
Escrituras De CRÉDito A RIESGo Suscritas PARA la flota De Diego Nicuesa (1508-1509) (Continuación)

\begin{tabular}{|c|c|c|c|c|}
\hline Otorgante & $\begin{array}{l}\text { Prestamistas } \\
\text { y cargadores }\end{array}$ & Origen & Valor & $\begin{array}{c}\text { Objeto de la } \\
\text { escritura }\end{array}$ \\
\hline El mismo & $\begin{array}{l}\text { Alejandro Cattaneo y } \\
\text { Alonso Alemán }\end{array}$ & mercader genovés & $(i ?)$ & préstamo \\
\hline El mismo & Jerónimo de Ervás & mercader aragonés & $33.075 \mathrm{mrs}$. & vinagre \\
\hline El mismo & $\begin{array}{l}\text { Bernardino de la Isla } \\
\text { (fiadores: Juan Farfán, } \\
\text { Diego Nicuesa y Juan } \\
\text { de Güemes, mercader) }\end{array}$ & $\begin{array}{l}\text { mercader y jurado } \\
\text { sevillano }\end{array}$ & $45.100 \mathrm{mrs}$. & $\begin{array}{l}250 \text { arrobas de vino, } \\
325 \text { varas de lienzo } \\
\text { y otras mercancías }\end{array}$ \\
\hline Juan Farfán & Juan de Güemes & mercader & & $\begin{array}{l}15 \text { toneladas de } \\
\text { mercancías, } 2 \\
\text { becerras y un asno } \\
\text { para venta en Santo } \\
\text { Domingo }\end{array}$ \\
\hline Diego de Nicuesa & $\begin{array}{l}\text { Pedro de Santo } \\
\text { Domingo }\end{array}$ & mercader burgalés & 22 ducados & 《ciertas mercancías» \\
\hline Diego de Nicuesa & $\begin{array}{l}\text { Pedro de Santo } \\
\text { Domingo }\end{array}$ & mercader burgalés & 157 ducados & «ciertas mercancías» \\
\hline $\begin{array}{l}\text { Diego Nicuesa y } \\
\text { Cristóbal Maya, } \\
\text { cómitre }\end{array}$ & Pedro de Jerez & $\begin{array}{l}\text { cambiador } \\
\text { sevillano }\end{array}$ & 75 ducados & préstamo \\
\hline $\begin{array}{l}\text { Juan de Barrantes, } \\
\text { v. }{ }^{\circ} \text { de Lequeitio, } \\
\text { maestre, Antonio } \\
\text { Serrano, v. }{ }^{\circ} \text { Sto. } \\
\text { Domingo, Diego } \\
\text { Nicuesa, v. } .^{\circ} \text { La } \\
\text { Concepción }\end{array}$ & Bernardino de la Isla & jurado sevillano & $124.480 \mathrm{mrs}$ & $\begin{array}{l}\text { venta de } 2.741 \text { varas } \\
\text { de lienzo y } 189 \\
\text { varas de holandas }\end{array}$ \\
\hline Diego de Nicuesa & Martín de Salcedo & mercader & 217 ducados & préstamo \\
\hline $\begin{array}{l}\text { Diego de Nicuesa, } \\
\text { Américo Vespu- } \\
\text { cio, Juan de } \\
\text { Ledesma y Juan } \\
\text { de Quicedo }\end{array}$ & Bernardino de la Isla & jurado sevillano & $22.500 \mathrm{mrs}$. & $\begin{array}{l}\text { venta } 20 \text { piezas de } \\
\text { lonas }\end{array}$ \\
\hline Diego de Nicuesa & Martín de Salcedo & mercader & 362 ducados & préstamo \\
\hline Diego de Nicuesa, & $\begin{array}{l}\text { Antón de Salas, } \\
\text { Francisco de Porras, } \\
\text { Diego de Ervás, } \\
\text { Bartolomé Díaz, } \\
\text { Américo Vespucio, } \\
\text { Juan de Caicedo, } \\
\text { Fernando de Ávila y } \\
\text { Diego López }\end{array}$ & $\begin{array}{l}\text { notario apostólico } \\
(---) \\
\text { mercader } \\
\text { cómitre } \\
\text { piloto } \\
(---) \\
(---) \\
(---)\end{array}$ & & \\
\hline
\end{tabular}


Escrituras de crédito a Riesgo suscritas Para la flota de Diego Nicuesa (1508-1509) (Continuación)

\begin{tabular}{|l|l|l|l|l|}
\hline \multicolumn{1}{|c|}{ Otorgante } & \multicolumn{1}{|c|}{$\begin{array}{c}\text { Prestamistas } \\
\text { y cargadores }\end{array}$} & \multicolumn{1}{c|}{ Origen } & \multicolumn{1}{c|}{ Valor } & \multicolumn{1}{c|}{$\begin{array}{c}\text { Objeto de la } \\
\text { escritura }\end{array}$} \\
\hline Diego de Nicuesa & Otavián Calvo & mercader genovés & & \\
\hline $\begin{array}{l}\text { Diego de Nicuesa } \\
\text { y Juan de Ledesma }\end{array}$ & Francisco de Escobar & & $12.000 \mathrm{mrs}$. & 300 arrobas de vino \\
\hline $\begin{array}{l}\text { Diego de Nicuesa } \\
\text { y Juan de Ledesma }\end{array}$ & Juan de Segura & mercader vizcaíno & $20.000 \mathrm{mrs}$. & $\begin{array}{l}\text { una partida de } \\
\text { tocinos }\end{array}$ \\
\hline Diego de Nicuesa & Pedro de Villadiego & sevillano & $15.000 \mathrm{mrs}$. & ciertas lonas \\
\hline $\begin{array}{l}\text { Juan de Ledesma } \\
\text { y Juan de Caicedo }\end{array}$ & Juan de Burgos & mercader burgalés & $14.300 \mathrm{mrs}$. & ciertos lienzos \\
\hline $\begin{array}{l}\text { Diego de Nicuesa, } \\
\text { Juan de Ledesma } \\
\text { y Juan de Caicedo }\end{array}$ & Thomas Malliard & mercader inglés & $102.000 \mathrm{mrs}$. & $\begin{array}{l}\text { camisas y calzones, } \\
\text { harinas y pasas }\end{array}$ \\
\hline
\end{tabular}

Las obligaciones que se nos han conservado sobre los cargamentos de las cuatro naves de Nicuesa y que incorporamos en el cuadro de arriba demuestran una vez más el carácter colectivo del comercio trasatlántico y sus consabidas fórmulas crediticias, tantas veces subrayados por E. Otte, A. M. Bernal, C. Martínez Shaw, J. M. Oliva y otros especialistas del tráfico americano. En este complejo entramado intervienen junto a los profesionales del comercio otra gente de muy diversos oficios metidos a mercaderes, comenzando por el propio Nicuesa - quien se nos revela en este estudio en una faceta absolutamente desconocida de armador y comerciante-, así como maestres, pasajeros y cambiadores. El procurador de los vecinos de Santo Domingo y compañero de Nicuesa, bachiller Antonio Serrano, quien durante su estancia en la capital hispalense se hace llamar licenciado, adelanta su regreso a las Indias, pues viaja en el mes de junio acompañando al virrey Diego Colón. No obstante, tiene tiempo para cargar mercancías en la flota de su amigo Nicuesa y en sociedad con este. Todos ellos envían a vender a las Indias telas, vino, materiales de construcción (ladrillos), ganado y otros muchos y variados objetos. También consta que se embarcaron en la flotilla del gobernador de Veragua 50 esclavos negros, 40 yeguas y otros tantos caballos, en virtud de la licencia concedida por el monarca para la expedición ${ }^{51}$. Entre los mercaderes implicados en el negocio atlántico destacan genoveses y burgaleses. Es sabido que

51 Rls. Cédulas a los oficiales de la Contratación, todas datadas en Burgos el 6 de julio de 1508. AGI, Indiferente, 1961, L.1. 
solamente un mercader genovés, Bernardo Grimaldi, desde su naturalización en 1507, puede legalmente tratar con las Indias. Pero en esta ocasión, como anteriormente en la flota del virrey Colón, la presencia genovesa es bien manifiesta lo cual, como indica Otte, demuestra que estos no tuvieron dificultades para intervenir en el comercio con América ${ }^{52}$. Aquí y allá encontramos involucrados en la flota de Nicuesa a los más famosos genoveses de aquella época: los Grimaldi, Doria, Spínola, Centurión, Cattaneo y otros. Sin olvidar la participación como proveedor de mercancías del famoso mercader inglés Thomas Malliard, cuyos negocios en la Sevilla del XVI fueron ya señalados por Otte ${ }^{53}$. Tres de los cargadores son grandes personajes sevillanos: Bernardino de la Isla, Pedro de Santo Domingo y Juan de Burgos. El primero es jurado de la ciudad y receptor de la alhóndiga en 1504 y 1505; proveedor junto a otros tres mercaderes burgaleses de trigo para la ciudad en el año del hambre de 1505 y fundador de una capilla en la iglesia de El Sagrario. Los otros dos son mercaderes burgaleses, de notable reputación, que desde hace años se han establecido en Sevilla. Todos han remitido mercancías a las Indias en la flota de Diego Colón que ha zarpado este año: Bernardino de la Isla carga en seis naves; Pedro de Santo Domingo en siete y Juan de Burgos en tres ${ }^{54}$. No deja de sorprender el protagonismo que exhibe en el negocio atlántico el veedor Juan de Caicedo, quien antes de embarcarse para las Indias da muestras de disfrutar de una envidiable situación económica. A este lo encontramos plenamente involucrado en el trasiego del tráfico, ya sea embarcando toda suerte de mercancías para venderlas en La Española, ya como fiador del maestre Juan de Farfán e incluso aportando capitales para la empresa del gobernador. Se conserva una curiosa escritura de 13 de marzo de 1509. En la fecha citada comparece Nicuesa ante el escribano Juan Ruiz de Porras y otorga una carta de obligación, por una cuantía que no precisa el documento, con un grupo variopinto de socios, comenzando por el citado Juan de Caicedo, quien declara ser vecino de Sevilla, en la collación de Santa María Magdalena, así como el famoso piloto Américo Vespucio, el notario apostólico Antón de Salas, Francisco de Porras, el mercader sevillano Diego de Ervás, el bien conocido cómitre de la reina y trianero Bartolomé Díaz, Fernando de Ávila, hijo del

52 Otte, 1964a: 479.

53 Cfr. Otte, 1964a: 321. Thomas Malliard y Robert Thorne fueron arrendatarios de las almonas de Sevilla y pertenecieron al grupo de los mercaderes más poderosos de Sevilla en esta época. Thomas Malliard explotó la fábrica de jabón de Triana junto con el jurado de Sevilla Juan Díez de Alfaro en 1521-1522 y Robert Thorne en sociedad con el mercadés genovés Leonardo Cattaneo y el banquero Alonso de Melgar en 1522-1531. Como puede observarse, ya en 1509 Malliar negociaba con América. Otte, 2010: 277.

54 Otte, 1964a: 480. 
contador Diego de Ávila, vecino de Sevilla en la collación de San Esteban y Diego López, mayordomo del señor Fernando Enríquez de Ribera en la collación de San Juan ${ }^{55}$. En otra, no menos reseñable, suscrita el 12 de junio de 1509 ante los oficiales de la Casa de la Contratación de Sevilla ${ }^{56}$, de nuevo encontramos a Américo Vespucio, el piloto mayor de las Indias, actuando en comandita con Nicuesa, Juan de Ledesma y el veedor Caicedo en la compra de una partida de lonas con destino a La Española, por importe de 22.500 maravedís, y asumiendo la deuda correspondiente con el jurado sevillano Bernardino de la Isla, que las suministró. En ella, el famoso piloto mayor, por carecer de liquidez, recurre a su salario como garantía de pago, declarando lo siguiente: «E yo, el dicho Américo Vespucio hipoteco para cumplir lo susodicho la quitación e salario que de Su Alteza tengo en esta dicha Casa». Involucrado en el tráfico y en innumerables operaciones crediticias, que suscribe casi todas ellas en los meses inmediatos a la salida de la flota, Diego de Nicuesa se intitula en cuantos documentos suscribe ante los mismos oficiales de la Casa de la Contratación "gobernador de Urabá y Veragua», apropiándose indebidamente de un cargo que no le corresponde ya que, como es sabido, la gobernación de Urabá había sido otorgada a su compañero Alonso de Ojeda.

Por cierto, resulta más que probado que Diego de Nicuesa, una vez en Santo Domingo, no utilizó una de las naves que había adquirido en España para transportar a sus hombres a la conquista de Veragua, ya que esta regresó a Sevilla. Según lo indican los documentos notariales sevillanos, referidos al año de 1510, Juan de Farfán, el maestre de La Trinidad, se encontraba ya en enero del citado año en el puerto sevillano de las Muelas, admitiendo carga para un nuevo viaje a Santo Domingo, y suscribiendo numerosos préstamos a «riesgo y ventura», siempre por delegación del dueño de la nao que seguía siendo Nicuesa.

\section{La EXPEdición DE TIERRA Firme}

El 4 de septiembre de 1509 la flotilla de la Tierra Firme y los dos barcos que iban en conserva con las remesas de Santo Domingo zarpaban desde Sanlúcar de Barrameda ${ }^{57}$. A bordo iban los 200 hombres a los que el sobera-

\footnotetext{
55 APS, 1508. Libro del año 1509. Fecha: 13, marzo. Oficio III, Escribanía Juan Ruiz de Porras.

56 AGI, Documentos Escogidos, 1, N. 5.

57 «En cuatro de septiembre de quinientos e nueve dio por cuenta Lorenzo de Pinelo, alguacil de Sus Altezas, haber gastado en Sanlúcar al tiempo de la partida de las dos carabe-
} 
no dio licencia para marchar. Un buen grupo procedía de la localidad sevillana de Écija. Hacía poco que el virrey Diego Colón había abandonado la capital hispalense, rumbo a La Española, con su flota de nueve naves y un numeroso contingente, y es probable que Nicuesa tuviera dificultades para reclutar a su hueste. En el mes de julio los preparativos se aceleran. Nicuesa contrata en este mes a Juan García, un herrero de Sanlúcar la Mayor (Sevilla) para servirle durante tres años en la provincia de Veragua, para lo cual este se compromete a llevar consigo «su fragua y herramientas en la armada que marcha a poblar la Tierra Firme» ${ }^{58}$. Días más tarde, el gobernador firma en la escribanía de Manuel Segura un contrato con un grupo de personas que se obligan a servirle en la Tierra Firme. Se trata de Marcos Rabal, natural de Albacete, Pedro de Cospedal, asturiano, Rodrigo de Torres, natural de Trigueros, Gonzalo Martínez (¿?), natural de Trebejo, Sebastián Báez, vecino de Monterrey y Juan Sierra, asturiano ${ }^{59}$. A última hora, agosto de 1509, y en vista de que en la capital hispalense no consigue hacerse con la gente necesaria, comisiona a un labrador de Écija, llamado Juan Carmona, para que contrate en su localidad de origen hasta cincuenta personas dispuestas a acompañarle en aquella aventura ${ }^{60}$. El flujo migratorio de los ecijanos a las nuevas tierras parece que no cesa. Meses atrás el alcalde mayor del virrey Colón, Marcos de Aguilar, acababa de reclutar también en Écija a un buen número de vecinos y familiares, entre ellos su pariente Jerónimo de Aguilar, quien aún desconocía lo que el destino le tenía reservado ${ }^{61}$.

En este viaje, Nicuesa se hacía acompañar por un pequeño paje negro, apenas un muchacho, que le fue arrebatado nada más llegar a Santo Domingo porque iba sin registrar ${ }^{62}$. El piloto Juan de la Cosa llevaba a su esposa Te-

las de Su Alteza 6.100 maravedís en esta manera: en dos botas de vino, que dio sendas a cada una de las dos carabelas que costaron 2.594 maravedís, e dos quintales de bastina, que costaron 784 maravedís, e dos ducados de carne y 272 maravedís de aceite e 68 maravedís de candelas y 238 maravedís que pagó por adobar las cadenas de las mesas y otros capítulos»». AGI, Contratación, 4674, L.1.

58 APS, 2184. Libro del año: 1509, 23, julio. Oficio IV, Lib. III, Escribanía Manuel Segura.

59 Idem.

${ }^{60}$ Libro del año 1508-1509-1542. Oficio III. Escribanía Juan Ruiz de Porras. Fecha: 1, agosto, 1509. Fondo Enrique Otte. Agradecemos al profesor Jaime Lacueva su colaboración y atenciones permitiéndonos el acceso al valioso legado de E. Otte, que él mismo ha inventariado.

61 Otte, 1964a: 477. Una vez en Santo Domingo, Jerónimo de Aguilar se alistó con Diego de Nicuesa y se perdió en las costas de Yucatán donde anduvo varios años prisionero de los indios. Fue rescatado y se convirtió en el intérprete de Cortés junto a la Malinche.

62 Una Real Cédula dirigida al tesorero Miguel de Pasamonte, ordenaba que el citado esclavo le fuese devuelto a Diego de Nicuesa y en caso de que este hubiese muerto a su 
resa, a sus hijos y a dos esclavas cristianas para su servicio ${ }^{63}$, a los que pensaba dejar convenientemente instalados en Santo Domingo, mientras durase la aventura. La Corona, queriendo recompensar una vez más los servicios del experimentado piloto de la Contratación, Juan de la Cosa, había ordenado al virrey Colón que le facilitase una vivienda digna para alojar a su familia y una encomienda de indios en La Española ${ }^{64}$. También viajaban a cargo de la Corona cinco frailes de la Orden de Santo Domingo y un seglar. Un asiento del tesorero Matienzo, de 24 de marzo de 1511, hace constar cómo en la citada fecha se había abonado a Juan de Farfán, maestre de una de las embarcaciones de Diego Nicuesa, y al mercader genovés Jácome Grimaldo, en su nombre, 6.750 maravedís por el pasaje y mantenimiento del citado grupo ${ }^{65}$. Entre el personal eclesiástico que acompañaba a Nicuesa se encontraba también el presbítero Pedro Sánchez, vecino de Sevilla, y otro sevillano y luego conquistador del Darién, llamado Diego Fernández ${ }^{66}$.

Como ya vimos, los flamantes alcaides de las fortalezas de la Tierra Firme fueron distinguidos al mismo tiempo con el oficio de veedores de los rescates en sus respectivos territorios. Ambos retrasaron su partida y no viajaron en la flotilla que llevaba a Nicuesa a Santo Domingo. Alonso de Quiroga, el designado para la gobernación de Urabá fue el primero en zarpar, probablemente en diciembre de $1509^{67}$. Llevaba su yegua y se hacía acompañar por un es-

hermano Alonso o a quien tuviere su poder. Burgos, 12, agosto, 1512. AGI, Indiferente, 419, L.4, F.1r-1v.

63 Real Cédula a los oficiales de la Casa de la Contratación. Valladolid, 15, junio, 1509. AGI, Indiferente, 1961, L.1.

${ }^{64}$ Real Cédula a Nicolás de Ovando. Burgos, 17, junio, 1508. AGI, Indiferente, 1961, L.1. A la muerte del famoso piloto, acaecida en las costas de Cartagena en noviembre de 1509, la Corona concedió a su viuda Teresa una ayuda para el casamiento de la hija de ambos de 45.000 maravedís. Data del libro del tesorero Matienzo de 31 de marzo de 1511. Ladero, 2002: 156 .

65 Ladero, 2002: 155.

66 Información de los méritos y servicios de Pedro Sánchez, presbitero, uno de los que fueron desde España en la armada de Diego Nicuesa hasta la provincia de Veragua. Santa María de la Antigua, 20, agosto, 1514. AGI, Patronato, 150, N1, R.1. Información de méritos y servicios de Diego Fernández o Hernández, vecino de Sevilla que pasó a la Tierra Firme en 1509 con Nicuesa (desde Sevilla). Sevilla, 5, abril, 1531. AGI, Patronato, 150, N.4, R.1.

${ }^{67}$ Real Cédula por la que se nombra a Alonso de Quiroga como veedor de los rescates con Diego de Nicuesa. Valladolid, 1, septiembre, 1509. AGI, Indiferente, 418, L.2, F. 52v-53r. El 8 de diciembre de 1509 el tesorero Matienzo abonó a Alonso de Quiroga veinte ducados de oro por el pasaje y mantenimientos para él y para un esclavo y una yegua «que Su Alteza le mandó pagar». Ladero, 2002: 146. Véase también Real Cédula a los oficiales de la Contratación, de 12 de noviembre de 1509, en la que se disponía que dejasen a Silvestre Pérez sacar libremente un esclavo y una yegua para la Tierra Firme. AGI, Indiferente, 1961, L.1. 
clavo negro y por su criado Lorenzo, que era natural de Zalamea la Real (Huelva). El nombramiento de Silvestre Pérez como alcaide de las fortalezas de Veragua no se produjo hasta 1510 , de manera que no pudo abandonar Sevilla hasta la primavera de ese año ${ }^{68}$. Lo hizo en la nave del maestre Juan de Camargo, e iba acompañado de varios criados, uno de ellos se llamaba Antonio de Gamboa y era natural de Hita. Juan de Caicedo (Quicedo) el flamante veedor de las fundiciones de la Tierra Firme por nombramiento firmado en octubre de 1508 estaba avecindado en Sevilla en la collación de San Salvador y viajó a las Indias junto a su esposa Inés de Escobar69. Por último, como teniente de Lope de Conchillos, el poderoso secretario del rey, que ostentaba en aquellos años el oficio de la fundición, marcación del oro de las Indias - compartido con su compañero Miguel Pérez de Almazán—, así como la escribanía mayor de minas, fue nombrado un anónimo Pedro Mir, de quien no se conserva noticia alguna en el Darién ${ }^{70}$. Finalmente la expedición «para la población de la Tierra Firme» costó a la Corona algo más de dos millones de maravedís ${ }^{71}$.

También para el nuevo gobernador de Veragua la aventura que ahora emprendía le había supuesto un considerable desembolso. Abandonó el muelle de las Muelas, agobiado por los requerimientos de los acreedores y por innumerables deudas, gran parte de las cuales nunca pudo devolver, pues la

68 Orden a los oficiales de la Casa de la Contratación para que ayuden a Silvestre Pérez que va como veedor de Tierra Firme a la parte de Urabá, donde va por gobernador Alonso de Ojeda. Madrid, 23, marzo, 1510. AGI, Indiferente, 418, L.2 y Contratación, 5536, L.1. Registro del libro de cuentas de Matienzo, de 22 de abril de 1510, por el que se abona a Silvestre Pérez 13.400 maravedís por un tercio de su quitación como veedor de los rescates y otros 7.500 maravedís por su pasaje y el de «ciertos criados suyos». Ladero, 2002: 149. Silvestre Pérez solo desempeñó su cargo trece meses, pues falleció en Darién. En 1513, los oficiales de la Contratación recibían órdenes de abonar 30.050 maravedís, resto del salario devengado al veedor, a Sena Pérez, su hija. AGI, Panamá, 233, L.1.

69 Real Provisión nombrando a Juan de Caicedo, veedor del oro y otros metales que se encuentren y fundan en Tierra Firme, donde van Diego de Nicuesa y Ojeda. Córdoba, 5, octubre, 1508, L.1, f. 77 v-78. En 1513 regresó a España en compañía de Rodrigo de Colmenares, ambos como procuradores de los vecinos del Darién, para protestar por los abusos de Balboa. Nombrado una vez más en 1513 como veedor Tierra Firme. Tenía previsto regresar al Darién al año siguiente en la flota de Pedrarias, pero una enfermedad inesperada acabó con su vida y murió en Sevilla «tan hinchado y amarillo como el oro que había ido a buscar». Su viuda e hijos permanecieron por largo tiempo residiendo en Nuestra Señora de la Antigua.

70 Real Cédula a Diego de Nicuesa y Alonso de Ojeda, para que admitan a Pedro Mir., Sevilla, 8, diciembre, 1508. Indiferente, 1961, L.1. Otra cédula de la misma fecha a los oficiales de la Contratación para que dejen pasar libremente dos yeguas que lleva Pedro Mir. AGI, Indiferente, 1961, L.1.

71 Ladero, 2008: 36. 
muerte lo esperaba poco tiempo después en medio del océano ${ }^{72}$. Ya de camino a Santo Domingo y cuando se encontraban a unas doce leguas de la isla de San Juan, los barcos de Nicuesa recibieron orden de hacer escala en la isla de Santa Cruz y luego en el mismo San Juan para saltear indios. Seguramente el gobernador pensaba resarcirse con el producto de este tráfico inhumano de parte de las deudas contraídas en España. La ranchería fue devastadora: doscientos indios fueron capturados y luego vendidos como esclavos en Santo Domingo. El fraile Las Casas cuenta que la llegada a La Española de este nuevo cargamento humano provocó un gran escándalo entre los vecinos, y aunque no era cierto, Nicuesa se justificó diciendo «que trajo licencia del rey para hacerlo» ${ }^{73}$. Cuando estos hechos llegaron a oídos de la Corona fueron severamente reprobados dándose orden de restituir todos ellos a sus tierras ${ }^{74}$.

\section{El virRey Diego Colón y la Gobernación del DariéN}

Desde el momento en que se conocieron las capitulaciones para la conquista de Veragua y Urabá la actitud del virrey Diego Colón fue abiertamente opuesta. Se habían violado los privilegios de su padre sobre aquellas tierras que él mismo había descubierto. ¿Cómo iba a consentir que un intruso se beneficiase de aquella gesta? Y no solo era Veragua, también la isla de Jamaica, descubierta por el Gran Almirante, había sido concedida a dos intrusos, y don Diego hizo cuanto pudo para adelantarse a lo que ya eran hechos consumados ${ }^{75}$. Intentará oponerse primero en la corte y al no conseguir sus propósitos proseguirá luego en Santo Domingo. Nada más ajustado a los hechos

72 La pesada «herencia» recayó sobre su hermano y único heredero, Alonso de Nicuesa.

73 De este suceso que sin duda provocó un gran revuelo en La Española, se hizo eco Bartolomé de las Casas, 1955, vol. II: 128.

74 Real Cédula a Diego de Nicuesa y Alonso de Ojeda. Madrid, 28, febrero, 1510. AGI, Indiferente, 418, L.2. Más adelante la orden fue revocada. Una Real Cédula dirigida a Diego Colón y a los jueces de apelación de la Audiencia de Santo Domingo, de 30 de julio de 1512, ordenaba que restituyesen a Alonso de Nicuesa, los doscientos indios que su hermano Diego de Nicuesa, difunto, trajo como esclavos de las islas comarcanas a La Española o los devolviesen a las personas que Diego de Nicuesa dejó allá con su poder. AGI, Indiferente, 418, L.3.

75 Anota Las Casas (1955, vol. II: 129) que «como el Almirante de ambas gobernaciones por muy agraviado se sintiese, mayormente, como se dijo de la de Veragua y Jamaica, todo cuanto pudo contrarió al despacho de ellos, y para impedirles lo de Jamaica, determinó de enviar a poblarla, y a aquel caballero de Sevilla, Juan de Esquivel... por su teniente de ella». 
—dice Luis Arranz - que aquellas palabras premonitorias del virrey: «sea Dios testigo que si no va por mano de Su Alteza y de quien en La Española reside, que nunca harán fruto» ${ }^{76}$. Por lo pronto, se dedicó a estorbar el apresto de la flota de Tierra Firme y por mano de su alcalde mayor retrasó cuanto pudo la salida de Nicuesa hacia Veragua, moviendo a los acreedores para que le embargasen sus bienes e impidiesen la partida. Y por si esto fuera poco, ordenó desposeerle de su encomienda de indios contraviniendo abiertamente lo dispuesto por la Corona ${ }^{77}$. Al mismo tiempo, determinó emprender por su cuenta la conquista de Jamaica, enviando por su teniente al hidalgo sevillano Juan de Esquivel al frente de una expedición pobladora de 60 hombres, bien equipados y en continuo contacto con Santo Domingo. Alonso de Ojeda tampoco lo tuvo fácil. Cuenta Las Casas que el flamante gobernador de Urabá, agotado por tantas deudas y desesperado por la obstinación del almirante, montó en cólera y aunque no podía hacer nada para evitar que Esquivel y sus hombres cumpliesen las órdenes del virrey, se dirigió al puerto y con el puño en alto, mirando a los ojos a Esquivel, le dijo «que juraba que si entraba en la isla de Jamaica, que le había de cortar la cabeza ${ }^{78}$. La amenaza no surtió el efecto deseado. Muy pronto Juan de Esquivel ponía rumbo a Jamaica con una pequeña flotilla de sesenta hombres con la intención de conquistarla y poblarla ${ }^{79}$.

El Almirante se negó también con firmeza a acatar las órdenes de la Corona e impidió la recluta de los otros seiscientos hombres, avecindados en Santo Domingo, que contemplaba el asiento de Burgos. Solo permitió la salida de doscientos vecinos, alegando que si consentía en este éxodo masivo la isla quedaría despoblada y su economía en ruinas. Una Real Cédula de la reina Juana dirigida a Diego Colón, fechada en Madrid el 28 de febrero de 1510, autorizaba lo dispuesto por el virrey: «ya sabéis que en cierto asiento

76 Arranz, 1982: 9.

77 Real Cédula a Nicolás de Ovando para que guarde a Diego de Nicuesa y Ojeda los indios y haciendas que tienen en La Española durante los 4 años que dure el asiento. Burgos, 6, julio, 1508. AGI, Indiferente, 1961, L.1, f.55. El incumplimiento de lo dispuesto por el soberano abriría un interminable pleito entre Alonso de Nicuesa, hermano y heredero de Diego, ya fallecido y Diego Colón. AGI, Justicia, 1. Véase también: «Los herederos de Diego Nicuesa con el Almirante de las Indias don Luis Colón y sus herederos sobre cobranza de 2.000 pesos de oro». Año 1566. AGI, Justicia, 979.

78 Las Casas, 1957, vol. II: cap. LII.

79 Más adelante la corona permitiría la intervención del virrey Colón sobre la gobernación de Jamaica: «Real Cédula a Diego Colón para que el almirante nombre un veedor que vigile la gobernación de Ojeda y Nicuesa en la isla de Jamaica». Madrid, 28, febrero, 1510. AGI, Indiferente, 418, L.2, F. 115r-115v. 
y capitulación que el rey, mi señor e padre, mandó tomar con Diego de Nicuesa e Alonso de Ojeda sobre la población de la Tierra Firme se les dio facultad que de esa isla Española pudiesen ir seiscientos hombres, los que quisiesen ir con ellos e que estos gozasen de los indios e heredades que tuviesen en la isla Española... he sido avisada que en esto la dicha isla recibiría mucho daño (y por tanto) he acordado que sean en el dicho número de doscientas personas e que los que así pasaren los indios e naborías e haciendas que tuvieren para que gocen de ellos el tiempo que estuvieren en la dicha Tierra Firme si ahí residiesen» ${ }^{80}$. No obstante la soberana admitía que «Si Nicuesa y Ojeda quisieren para completar los seiscientos a otros que no tuvieren vecindad ni indios, dénseles». El cronista Anglería con una desbordada imaginación asegura que abandonaron La Española en compañía de Ojeda y Nicuesa un total de 1.085 hombres $^{81}$. Las Casas, que por aquel entonces se encontraba en la isla dice que Nicuesa consiguió embarcar 700 hombres en cinco barcos y dos bergantines, mientras que Ojeda con dos navíos y dos bergantines reclutó solo a $300^{82}$. Es evidente que ambos exageraban... Seguramente confiado en la veracidad del relato de los cronistas, Luis Arranz afirma que «a pesar de las dificultades y obstaculizaciones que tuvieron que pasar, salieron de La Española, entre finales de 1509 y el año 1510, más de mil españoles en las armadas de Hojeda, Nicuesa y en las que Enciso y Colmenares llevaron meses más tarde para socorrer a dichos capitanes ${ }^{83}$. Rodrigo de Colmenares, el teniente de Nicuesa, constituye, hoy por hoy, el informante más veraz. En una carta a la Corona exponía que cuando llegó a la Tierra Firme casi toda la expedición había desaparecido, «pues de 800 que pasaron con ambos gobernadores (Nicuesa y Ojeda) no había 300 vivos». En el mismo informe, Colmenares aseguraba que Nicuesa llevaba 580 hombres, luego el grupo de Ojeda solo se compondría de 220.

En verdad que todo lo relacionado con el flujo migratorio a la Tierra Firme en los años de Nicuesa y Ojeda está muy enrevesado. La versión oficial se contradice con el abultado informe de los cronistas, mientras que los testigos de aquellos días se quejan con angustia de la falta de brazos y de armas para acometer la conquista de aquellas tierras, ante las numerosas bajas causadas en las escaramuzas con los indios. No debían sobrarles muchos hombres a Alonso de Ojeda cuando este reclama desesperado en 1511 el envío «de

80 AGI, Indiferente, 418, L.2. Del mismo tenor la Real Cédula en respuesta a la carta de Diego Nicuesa, datada en Tordesillas el 25 de julio de 1511. AGI, Indiferente, 418, L.3.

81 Anglería, 1989: 98.

82 Las Casas, 1957, vol. II: 120.

83 Arranz, 1983, vol. II: 78. 
algunos malhechores desterrados para la Tierra Firme», porque, según comentaba el monarca (los hombres) «no quieren ir allá a causa del disfavor que el almirante os da» ${ }^{84}$. No obstante, cualquiera podría alegar a favor del virrey que tal desplazamiento humano era el más numeroso de todos los concedidos para La Española en esta década y que llegó en el momento más inoportuno, cuando la economía insular comenzaba a remontar y su población a estabilizarse. De hecho para 1510 se calcula que la isla pudo disfrutar de una población bastante nutrida que alcanzaría según los cálculos más generosos a las diez o doce mil personas ${ }^{85}$, y es sabido que a partir de esta fecha se inicia el proceso expansionista hacia otras zonas del continente y, en consecuencia, la despoblación de la isla. No cabe duda de que este nutrido éxodo afectaba negativamente los planes expansivos del virrey. Recordemos que a partir de 1509 se inician los preparativos para reforzar las poblaciones de las islas de San Juan y Cuba y se emprende la conquista de Jamaica. Según Las Casas, para esta fecha un contingente de 300 vecinos abandonó La Española para emprender otra anexión: la de la isla de Cuba. En esta ocasión, como señala G. Morell, «Diego Colón no puso tantos impedimentos, sino que incluso apoyó la expedición dirigida por Diego Velázquez», fiel amigo y protegido del virrey ${ }^{86}$. En su empecinado forcejeo con la corona, Diego Colón consiguió pequeños retoques a su favor sobre la capitulación de 1508. Y además de reducir drásticamente el número de colonos para la Tierra Firme, obtuvo una cierta intervención sobre los asuntos de Jamaica mediante la facultad de poder nombrar a un veedor «que vigile la gobernación de Ojeda y Nicuesa» en la citada isla ${ }^{87}$. La última jugada del virrey para controlar la Tierra Firme y someterla a su virreinato tuvo lugar en 1511 cuando al tiempo que reconocía la dudosa autoridad de Vasco Núñez de Balboa, quien merecidamente se había ganado el título del «primer conspirador del Nuevo Mundo», lo nombraba «nuestro gobernador e capitán de la dicha provincia del Darién e que tengais por nos y en nuestro nombre la gobernación e capitanía de la dicha isla e provincia e juzgado de ella».

Como es sabido, la empresa encomendada a Diego de Nicuesa en las tierras de Veragua culminó en un rotundo fracaso. Aquella armada de aventu-

${ }^{84}$ Real Cédula a Alonso de Ojeda en respuesta a su carta. Tordesillas, 25 de julio, 1511. Indiferente, 418, L.3, F. 147r-148v.

85 Las Casas, 1957, vol. II: 336. Aceptan estos cálculos, entre otros, Arranz, 1983: 57. Rodríguez Morell se opone abiertamente a estas cifras y afirma que la isla no sobrepasaría en estas fechas las cinco mil personas: Año LXIX, vol. XXXII, núm. 117: 79-144. Por su parte, Las Casas afirma que La Española alcanzaba en esta época los diez o doce mil habitantes.

86 Rodríguez Morell, Año LXIX, vol. XXXII, núm. 117: 91.

87 Real Cédula a Diego Colón. Madrid, 28, febrero, 1510. AGI, 418, L.2. 
reros que felices y confiados había zarpado de Santo Domingo hacía apenas un año, quedó reducida a fines de 1510 a tan solo un puñado de hombres, todos hambrientos y enfermos. Nicuesa y otros muchos españoles que le acompañaban perdieron la vida en el intento y al final se replegaron hasta el golfo de Urabá buscando refugio en Santa María de la Antigua del Darién. Abandonado el proyecto colonizador, quedaba una frontera abierta, una especie de tierra de nadie, que seguía siendo objeto de reclamaciones por los herederos de Colón. Para contentarlos la corona concedió a Bartolomé Colón, hermano del virrey, el permiso para que en caso de que quisiera seguir descubriendo, se le permitiese poblar «la provincia de Veragua para que él tenga la gobernación por vos el Almirante y en vuestro nombre conforme a vuestros privilegios e declaración que por los del nuestro Consejo fue hecha de aquella tierra que en la dicha provincia fue descubierta por el almirante vuestro padre e por su industria y no más, con tanto que no exceda de los límites que el dicho almirante descubrió $\rangle^{88}$. Pero tales concesiones habían llegado demasiado tarde y no satisfacían las apetencias colombinas que se hacían extensivas a toda la Tierra Firme. Ante estas circunstancias solo quedaba acudir a la vía judicial. En consecuencia, el 3 de enero de 1512 Juan de la Peña, en nombre y representación de Diego Colón, reclamará ante el Consejo de Indias su derecho a la gobernación del Darién en la Tierra Firme. Se iniciaba así lo que conocemos como el interminable «Pleito del Darién» ${ }^{89}$.

\section{BiBLIOGRAFÍA}

Acosta, Antonio, «Intereses privados en la administración de la Monarquía. La Casa de la Contratación (1503-1535)», La Casa de la Contratación y la navegación entre España e Indias, A. Acosta, A. González y E. Vila (coords.), Sevilla, Universidad de Sevilla-CSIC-Fundación El Monte, 2003: 341-374.

Anglería, Pedro Mártir, Décadas del Nuevo Mundo, Introducción de Manuel Alba, Madrid, Polifeno, 1989.

Arranz Márquez, Luis, Repartimientos y encomiendas en la isla Española. (El repartimiento de Alburquerque de 1514), Madrid, Ediciones Fundación García Arévalo, 1991.

Arranz Márquez, Luis, Don Diego Colón, Madrid, CSIC, 1982, vol. I.

88 Real Cédula al Almirante, jueces y oficiales de La Española, 10 de diciembre de 1512. AGI, Indiferente, 419, Lib. IV, fol. 43 v. Citado por Arranz, 1982: 133.

89 Arranz, 1982: 130-131. 
Arranz Márquez, Luis, «Emigración española a Indias. Poblamiento y despoblación antillanos», América y la España del siglo XVI, 2 vols., edición a cargo de Francisco de Solano y Fermín del Pino, Madrid, CSIC, 1983, vol. II: 63-93.

Bernal, A. M., La financiación de la Carrera de las Indias (1492-1824). Dinero y crédito en el comercio colonial español con América, Madrid-Sevilla, Tabapress, El Monte, 1993a.

Bernal, A. M., «Maestres y señores de naos, con particular referencia a los onubenses y la financiación de la Carrera de las Indias (1492-1824)», Actas de las XI Jornadas de Andalucía y América, Huelva, Diputación Provincial de Huelva, 1993b, tomo I: $105-125$.

Carande, Ramón, Carlos V y sus banqueros. La vida económica en Castilla (15161556), Madrid, Sociedad de Estudios y Publicaciones, 1955.

Casas, Bartolomé de las, Historia de las Indias (estudio y notas de J. Pérez de Tudela), Madrid, BAE, 1957.

Catálogo de los fondos americanos del Archivo de Protocolos de Sevilla, Publicaciones del Instituto Hispano-Cubano, vol. 1, Madrid, 1930, vol. II, Sevilla, 1998.

Fernández de Oviedo, Gonzalo, Historia General y Natural de las Indias, 5 vols., Madrid, Ed. Juan Pérez de Tudela, BAE, 1959.

Fernández de Navarrete, Martín, Colección de los viajes y descubrimientos que hicieron por mar los españoles desde finales del siglo XV, 25 vols., Madrid, Ed. Seco Serrano, 1964.

Franco, Alfonso, «Las inversiones en Lebrija de Juan López de Recalde, contador mayor de la Casa de la Contratación», Cuadernos de Historia de España, 79/1 (Buenos Aires, enero-diciembre, 2005): 1-51.

García Fuentes, Lutgardo, Sevilla, los vascos y América. (Las exportaciones de hierro y manufacturas metálicas en los siglos XVI, XVII y XVIII), Bilbao, Fundación BBV/Laida, 1991.

García Fuentes, Lutgardo, «El Descubrimiento de América y el comercio de hierro y manufacturas del País Vasco: Reflexión sobre una oportunidad histórica frustrada», Actas del Congreso de Historia del Descubrimiento (1492-1556), Madrid, Real Academia de la Historia/Confederación Española de Cajas de Ahorros, 1992, vol. III: 655-681.

Giménez Fernández, Manuel, Bartolomé de las Casas. Vol. I: Delegado de Cisneros para la reformación de las Indias (1516-1517), vol. II: Capellán de S.M. Carlos I, poblador de Cumaná (1517-1523), Sevilla, E.E.H.A., 1953 y 1960.

Juan de la Cosa y la época de los descubrimientos. Catálogo de la exposición del mismo nombre, Santoña, Sociedad Estatal de Conmemoraciones Culturales, 2010 . 
Ladero Quesada, Miguel Ángel, El primer oro de América. Los comienzos de la Casa de Contratación de las Indias (1503-1511), Madrid, Real Academia de la Historia, 2002.

Ladero Quesada, Miguel Ángel, «La Casa de la Contratación de las Indias en sus comienzos: la tesorería de Sancho de Matienzo (1503-1510)», Acosta, A. González, A. y Vila, E. (coords.), La Casa de la Contratación y la navegación entre España e Indias, Sevilla, Universidad de Sevilla-CSIC-Fundación El Monte, 2003: 53-65.

Ladero Quesada, Miguel Ángel, Las Indias de Castilla en sus primeros años. Cuentas de la Casa de la Contratación (1503-1521), Madris, Dykinson, 2008.

Martínez Shaw, Carlos y Oliva Melgar, José M. (eds.), El sistema atlántico español (siglos XVII-XIX), Madrid, Marcial Pons, 2005.

Mena García, Carmen, Sevilla y las flotas de Indias. La Gran Armada de Castilla del Oro (1513-1514), Sevilla, Fundación el Monte/Servicio de Publicaciones Universidad de Sevilla, 1998, 2. ${ }^{a}$ edición, 1999.

Mena García, Carmen, El oro del Darién. Entradas y cabalgadas en la conquista de Tierra Firme (1509-1526), Sevilla, Centro de Estudios Andaluces (Consejería de Presidencia)-Consejo Superior de Investigaciones Científicas, 2011.

Otazu, A. y Díaz de Durana, J. R., El espíritu emprendedor de los vascos, Madrid, Silex, 2008.

Otte, Enrique, «Empresarios españoles y genoveses en los comienzos del comercio trasatlántico: la avería de 1507», Revista de Indias, 93-94 (Madrid, 1963): 519530 .

Otte, Enrique, «La flota de Diego Colón. Españoles y genoveses en el comercio trasatlántico de 1509», Revista de Indias, 97-98 (Madrid, 1964a): 475-504.

Otte, Enrique, «Los mercaderes vizcaínos Sancho Ortiz de Urrutia y Juan de Urrutia», Boletín Histórico, 6 (Caracas, 1964b): 5-32.

Otte, Enrique, Sevilla y sus mercaderes a fines de la Edad Media, Edición a cargo de A. M. Bernal y A. Collantes de Terán, Sevilla, Universidad y Fundación El Monte, 1996.

Otte, Enrique, Sevilla en el siglo XVI. Materiales para su historia económica. Edición a cargo de A. M. Bernal, A. Collantes, J. I. Martínez Ruiz y M. C. Ruiz León, Sevilla, Centro de Estudios Andaluces (CENTRA), 2010.

Ramos, Demetrio, Audacia, Negocio y Política en los viajes de «descubrimiento y rescate», Valladolid, Casa Museo Colón, Seminario Americanista de la Universidad de Valladolid, 1981.

Rodríguez Morell, Gerardo, «Desarrollo económico y cambio demográfico en La Española. Siglos XV-XVII», Boletín del Archivo General de la Nación, Año LXIX, Vol. XXXII/117: 79-144. 
Sauer, Carl O., The Early Spanish Main, Berkeley, University of California Press, 1966. La edición española: Descubrimiento y dominación española en el Caribe, México, Fondo de Cultura Económica, 1984.

Schäfer, Ernesto, El Consejo Real y Supremo de las Indias, 2 vols., Sevilla, Imprenta M. Carmona, 1935. Última edición: Salamanca, Junta de Castilla y León, Marcial Pons, 2003.

Szászdi León Borja, István, Los viajes de rescate de Ojeda y las rutas comerciales indias. El valor económico del señorío del mar de los Reyes Católicos, Santo Domingo, Ediciones Fundación García Arévalo, 2001.

Fecha de recepción: 4 de febrero de 2011

Fecha de aceptación: 1 de abril de 2001

\section{Diego de Nicuesa's preparations for the journey to populate the Tierra Firme. Seville and the merchants of the Atlantic trade (1509)}

On these pages we reveal absolutely new aspects of Alonso de Ojeda and Diego de Nicuesa's expedition to the Tierra Firme. In particular, we pay attention to the preparations carried out by Nicuesa in Seville, whose expenses and mishaps were reflected both in the accounts of Matienzo's Treasury book and Seville's notary records. In our research, a trading network emerges with a noticeable predominance of Basque and Genovese merchants interested in the Atlantic trade and who actively participated in the service of the flotilla of Tierra Firme.

Key words: Diego de Nicuesa; Alonso de Ojeda; Seville and the Atlantic Trade; credit risk texts; Juan de la Cosa; Tierra Firme; Basque, Genovese and Burgos, merchants. 